\title{
O USO DA TALIDOMIDA EM SERES HUMANOS E ANIMAIS - PASSADO, PRESENTE E FUTURO
}

Gabrielle Adad Fornazari ${ }^{1}$

José Ricardo Pachaly²

Fabiano Montiani-Ferreira

FORNAZARI, G. A.; PACHALY, J. R.; MONTIANI-FERREIRA, F. O uso da talidomida em seres humanos e animais - passado, presente e futuro. Arq. Ciênc. Vet. Zool. UNIPAR, Umuarama, v. 18, n. 1, p. 49-58, jan./mar. 2015.

RESUMO: A talidomida foi desenvolvida na década de 50 do século XX, e foi amplamente utilizada como um sedativo-hipnótico e como fármaco contra enjoos durante a gestação. No final da década de 60 ela foi retirada do mercado devido ao seu catastrófico efeito colateral de teratogenicidade. Contudo, o próprio mecanismo que é basicamente responsável pela sua teratogenicidade é também responsável por uma de suas muitas propriedades farmacológicas potencialmente benéficas e desejáveis, a anti-angiogênese. Felizmente, as pesquisas dos efeitos terapêuticos da droga não se cessaram e em 1998 o fármaco foi aprovado pelo Food and Drug Administration (FDA) para tratamento do eritema nodoso leproso e em 2006 para tratamento de mieloma múltiplo. Hoje, quase 40 anos depois, a mesma temida talidomida ressurge como fármaco de propriedades imunomoduladoras e antiangiogênicas, com potencial para tratamento de doenças inflamatórias, infecciosas e neoplásicas. Na medicina veterinária ainda pouco se sabe sobre os efeitos terapêuticos do fármaco, entretanto, o sucesso terapêutico do fármaco já fora observado em diversas situações clínicas em pessoas e em testes com animais, podendo existir indicação nas doenças homólogas na medicina veterinária. Este artigo traz uma revisão de literatura sobre a talidomida e suas aplicações reais e potenciais em medicina veterinária.

PALAVRAS-CHAVE: Angiogênese. Medicina veterinária. Talidomida.

\section{THE USE OF THALIDOMIDE IN PEOPLE AND ANIMALS - PAST, PRESENT AND FUTURE}

\begin{abstract}
Thalidomide was developed in the 1950's and was broadly used as a hypnotic-sedative drug and against nausea during pregnancy. At the end of the 1960's, the drug was withdrawn from the market due to its catastrophic side effect, teratogenicity. However, the anti-angiogenic action, which is the mechanism of action that is responsible for thalidomide's teratogenicity is also responsible for one of the several potentially useful and desired pharmacologic properties. Fortunately, investigations on the therapeutic effects of thalidomide did not cease and in 1998, the drug was approved by the Food and Drug Administration (FDA) to treat erythema nodosum leprosum and, in 2006, for treating multiple myeloma. Nowadays, almost 40 years later, the same feared thalidomide is reborn as a pharmacologic agent with immunomodulatory and anti-angiogenic properties, with potential to treat inflammatory, infectious and neoplastic diseases. In veterinary medicine, very little is known about the useful healing effects of thalidomide. However, the drug therapeutic success has already been noted in several clinical situations in both animal tests and investigations with medical patients. This paper presents a literature review of thalidomide's real and potential applications in veterinary medicine.
\end{abstract}

KEYWORDS: Angiogenesis. Chemotherapy. Veterinary medicine.

\section{EL USO DE TALIDOMIDA EN SERES HUMANOS Y ANIMALES - PASADO, PRESENTE Y FUTURO}

RESUMEN: La talidomida fue desarrollada en los años 50 del siglo XX, y fue ampliamente empleada como sedativo e hipnótico y como fármaco contra nauseas durante el embarazo. A finales de los años 60 ella fue retirada del mercado debido a su efecto secundario catastrófico de teratogenicidad. Sin embargo, el propio mecanismo que es básicamente responsable por su teratogenicidad es también responsable por una de las muchas propiedades farmacológicas potencialmente beneficiosas y deseables, la antiangiogénesis. Afortunadamente, las investigaciones de los efectos terapéuticos de la droga nunca se ha cesado y en 1998 el medicamento fue aprobado por Food and Drug Administration (FDA) para tratamiento del eritema nudoso leproso, y en 2006 para tratamiento del mieloma múltiple. Hoy, casi 40 años después, la misma y temida talidomida reaparece como medicamento con propiedades inmunomoduladoras y antiangiogénicas, con potencial para el tratamiento de enfermedades inflamatorias, infecciosas y neoplásicas. En medicina veterinaria, se sabe poco sobre los efectos terapéuticos del fármaco, sin embargo, el éxito terapéutico del medicamento se ha observado en varias situaciones clínicas en personas y en ensayos con animales, y puede ser indicado en las enfermedades homólogas en medicina veterinaria. Este artículo trae una revisión de literatura sobre la talidomida y sus aplicaciones reales y potenciales en medicina veterinaria.

PALABRAS CLAVE: Angiogénesis. Medicina veterinaria. Talidomida.

DOI: https://doi.org/10.25110/arqvet.v18i1.2015.5369

${ }^{1}$ Médica Veterinária, Mestranda do Programa de Pós Graduação em Ciências Veterinárias da Universidade Federal do Paraná - UFPR.

${ }^{2}$ Médico Veterinário, Mestre, Doutor, Pós-Doutor. Professor orientador no Programa de Pós Graduação em Ciência Animal da Universidade Paranaense UNIPAR.

${ }^{3}$ Médico Veterinário, Mestre, Pós Doutor. Professor Orientador no Programa do Programa de Pós Graduação em Ciências Veterinárias da Universidade Federal do Paraná - UFPR. 


\section{Introdução}

A talidomida é um fármaco derivado do ácido glutâmico, que possui longa e polêmica saga farmacêutica. Após ser lançada no mercado como sedativo "inteiramente atóxico", teve grande disseminação no mercado mundial, sendo indicada para tratamento doenças infecciosas febris, depressão leve, ansiedade, hipertireoidismo, tuberculose, sendo também utilizada como anti-emético. No final da década de 60 do século XX o fármaco foi retirado do mercado, graças a seus catastróficos efeitos teratogênicos. No total, foram quase 12.000 recém-nascidos apresentando malformações congênitas relacionadas a seu uso pelas mães, em diversos países (FERNÁNDEZ-CAMACHO; LEON-DORANTES, 2000).

Ao longo dos últimos 50 anos a talidomida tem sido alvo de investigações para seu uso em condições inflamatórias e oncológicas, em decorrência da identificação de efeitos imunomoduladores, anti-inflamatórios e antiangiogênicos. O reconhecimento desses efeitos proporcionou a possibilidade de avaliação de seu uso em diversas doenças oncológicas, inflamatórias e infecciosas, já estando atualmente aprovada para tratamento de eritema nodoso leproso e mieloma múltiplo.

Em medicina veterinária ainda se sabe muito pouco a respeito dos efeitos terapêuticos da talidomida, porém, em decorrência do sucesso em variadas afecções clínicas humanas similares às que ocorrem em animais, pode existir também indicação do fármaco para animais.

\section{Desenvolvimento}

\section{Histórico}

A talidomida é um composto racêmico neutro, derivado do ácido glutâmico, que foi sintetizado pela companhia farmacêutica suíça CIBA e introduzida no mercado, em 1957, sob o nome de Contergan ${ }^{\circledR}$, pela companhia farmacêutica alemã Chemie Grünenthal (D’AMATO et al., 1994). Nos primeiros ensaios clínicos foram testados os efeitos espasmolíticos, anestésicos locais e anticonvulsivantes da molécula, entre outros (LENZ, 1988). Porém, em decorrência do efeito mais observado ter sido depressão da atividade do sistema nervoso central, induzindo sono, a droga foi inicialmente indicada como agente sedativo (SHARDEIN, 1993).

O medicamento se disseminou rapidamente na época, pelas características alegadas de baixa toxicidade e por aparentar ação hipnótica muito eficaz. Os estudos préclínicos iniciais realizados em roedores não demonstravam taxas de letalidade significativas até mesmo quando altas doses foram utilizadas (KUMAR; WITZIG; RAJKUMAR; 2002). Neste tempo, os testes de toxicidade de fármacos empregando várias espécies de animais não eram exigidos (NG et al., 2002).

Assim, após ser lançado no mercado como sedativo “inteiramente atóxico", sem necessidade de prescrição médica, transformou-se em um dos medicamentos líderes de venda na Alemanha e foi comercializado com pelo menos 46 nomes diferentes pelo mundo (MATTHEWS; McCOY, 2003). Houve ainda, curiosa ampliação das indicações terapêuticas do medicamento por parte do fabricante, sendo sugerido para tratamento de irritabilidade, síndrome do pânico, ejaculação precoce, tensão pré-menstrual, distúrbios funcionais do estômago e vesícula biliar, doenças infecciosas febris, depressão leve, ansiedade, hipertireoidismo e tuberculose, e ainda como anti-emético (OLIVEIRA; BERMUDEZ; SOUZA; 1999).

Suas propriedades anti-eméticas aliadas às alegações de segurança inclusive para gestantes, tornaram-na muito atrativa para tratamento das náuseas durante a gestação, chegando a ser descrita como o melhor medicamento para ser administrado a gestantes e lactantes (D'ARCY; GRIFFIN, 1994). Também foram comercializadas associações de talidomida com outros compostos, para resfriados, tosse, cefaléia e asma, e uma apresentação na forma líquida era usualmente utilizada em hospitais alemães para sedar crianças durante exames eletroencefalográficos (STIRLING; SHERMAN; STRAUSS; 1997).

Apesar de ampla comercialização na Europa, Ásia e Américas, o fármaco não pôde ser comercializado nos Estados Unidos da América (EUA), por não possuir a licença pela agência norte-americana que regulamenta e controla o uso de fármacos e alimentos, a Food and Drug Administration (FDA). A aprovação não foi concedida em função de potenciais indícios da indução de neurite irreversível, e pela falta de estudos mais profundos quanto à sua segurança (MATTHEWS; McCOY, 2003).

Antes da utilização em mulheres gestantes, os efeitos teratogênicos da droga eram desconhecidos (MELCHERT; LIST, 2007). A partir de 1959, iniciaram-se os relatos médicos sobre nascimento de crianças com peculiar malformação congênita, caracterizada pelo desenvolvimento defeituoso dos ossos longos dos membros cujas mãos e pés variavam entre o normal e o rudimentar. Tal síndrome foi denominada focomelia, pela semelhança com as forma externa das focas (D'ARCY; GRIFFIN, 1994). Apesar da focomelia ser a malformação congênita mais difundida, foram descritas outras anomalias comprometendo diversos sistemas e órgãos, como ausência de orelhas, surdez, defeitos faciais e palatinos, e malformações do trato gastrintestinal (BORGES; GUERRA; AARESTRUP, 2005). No total, foram quase 12.000 recém-nascidos com malformações congênitas relacionadas com o uso da talidomida em diversos países (FERNÁNDEZCAMACHO; LEON-DORANTES, 2000). Em alguns casos, uma única administração no período crítico do desenvolvimento embrionário resultou em focomelia (POLITI, 2000). Segundo Rajkumar (2004), aproximadamente $40 \%$ das crianças afetadas morreram no primeiro ano de vida.

Diante das evidências, a droga foi retirada do mercado europeu em 1961. No Brasil, pela falta de informação quanto aos efeitos adversos que já haviam sido comprovados, o medicamento continuou sendo comercializado pelo menos até junho de 1962 (LENZ, 1988).

Em 1965, a utilização e a comercialização do medicamento já estavam banidas em quase todo o mundo, quando ocorreu uma descoberta fortuita em Israel, ao se empregar talidomida para sedação de pessoas com eritema nodoso leproso, e tais pacientes mostraram melhora inesperada das lesões dermatológicas logo após o início da terapia (SHESKIN, 1965). Essa descoberta desencadeou novo interesse na pesquisa, e em 1998 o fármaco foi aprovado pelo FDA para tra- 
tamento de eritema nodoso leproso e, em maio de 2006 para tratamento de mieloma múltiplo (CHEN et al., 2010).

Desde então, o número de doenças nas quais a talidomida pode ser utilizada como agente terapêutico vem aumentando a cada ano. Conforme Wu et al. (2005), há potencial terapêutico anti-inflamatório, imunomodulador e antiangiogênico, e consequentemente para tratamento em muitas formas de câncer. A droga também se mostrou eficaz no tratamento de síndromes mielodisplásicas (KUMAR et al., 2002).

\section{Estrutura química}

A molécula da talidomida basicamente é um derivado sintético do ácido glutâmico (LIMA; FRAGA; BARREIRO; 2011), e o fármaco existe sob a forma de isômeros ativos levógiros, e também na forma inativa racêmica - uma mistura dos dois isômeros na proporção de 1:1, que é usada clinicamente (JACOBSON, 2000). Tem pouca solubilidade em água, havendo apenas uma formulação oral como medicamento (TEO et al., 2002).

De acordo com Eriksson, Bjornkman e Hoglund (2001), a forma destrógira seria a responsável pelos efeitos sedativos e a forma levógira pelos efeitos teratogênicos e imunomoduladores. No entanto, os efeitos teratogênicos não poderiam ser evitados se fosse utilizada apenas a forma destrógira já que pode ocorrer uma rápida inversão quirálica entre os enantiômeros em pessoas, em pH fisiológico.

\section{Mecanismos teratogênicos propostos}

Existem atualmente mais de 30 hipóteses para os mecanismos da ação teratogênica da talidomida, agrupados em seis categorias, conforme o foco de acometimento: replicação ou transcrição do DNA, síntese e/ou função dos fatores de crescimento, síntese e/ou função das integrinas, angiogênese, condrogênese e morte ou lesão celular (STEPHENS; BUNDE; FILLMORE; 2000). Segundo Tabin (1998), o fármaco causa diminuição no crescimento do mesênquima do broto dos membros.

Segundo Christie (1962), os animais demonstram grande variedade de respostas à droga, com respostas teratogênicas variáveis - ratos e hamsters são mais resistentes à teratogenicidade, com maiores índices de reabsorção embrionária, enquanto coelhos e primatas são mais sensíveis, chegando a ter filhotes com as mesmas alterações teratogênicas tipicamente encontradas em pessoas (NEUBERT et al., 1999). Desta maneira, se espécies diferentes tivessem sido usadas nos testes iniciais, os efeitos teriam sido evidenciados, e o fármaco nunca seria aprovado (TEO et al., 2004). A ausência de efeitos teratogênicos em ratos é atribuída à baixa solubilidade em seu plasma destes, com baixo aporte do fármaco aos tecidos fetais (SCIALLI, 1992).

Dados epidemiológicos estabeleceram o período da gestação sensível à ação teratogênica em pessoas, definindo-se a janela teratogênica entre 34-50 dias após o fim do período menstrual, ou 20-36 dias após a fertilização (NEWMAN, 1986). Doses baixas como 50-100 mg já são capazes de induzir malformações típicas (SHARDEIN, 1993).

As malformações de membros são as mais comu- mente descritas, com defeitos usualmente bilaterais, mas não necessariamente simétricos. Há quatro grupos de defeitos, geralmente associados com membros torácicos encurvados ou com outros defeitos: 1. Focomelia (quatro membros curtos ou rudimentares), 2. Focomelia ou amelia (ausência total de membros torácicos, com outros defeitos em membros pélvicos, 3. Focomelia ou amelia de membros torácicos com membros pélvicos normais, 4 . Defeitos de membros pélvicos predominantes (hipoplasia femoral ou focomelia de extremidades inferiores) (SHARDEIN, 1993).

\section{Mecanismo de ação}

Os mecanismos que fundamentam as propriedades imunomoduladoras, anti-inflamatórias e antiangiogênicas da talidomida ainda não estão completamente entendidos, mas há modulação de citocinas inflamatórias como fator de necrose tumoral alfa $(\mathrm{TNF}-\alpha)$, fator nuclear $\kappa \mathrm{B}(\mathrm{NF}-\kappa \mathrm{B})$, IL12 (IL-12), ciclooxigenase 2 (COX-2) e interferon gama (IFN- $\gamma$ ) (FRANKS; MACPHERSON; FIGG; 2004). O fármaco é potente imunomodulador, com efeitos tanto na regulação de citocinas quanto na imunidade mediada por células. Um dos mediadores chave para a ação anti-inflamatória está no fator de necrose tumoral alfa (MELCHERT; LIST, 2007), que regula a cascata inflamatória e representa importante alvo no tratamento das doenças inflamatórias (MARRIOTT; WESTBY; DALGLEISH, 1997).

O fármaco pode diminuir o nível do TNF- $\alpha$ liberado por monócitos e macrófagos estimulados por endotoxinas por meio da degradação de seu RNA mensageiro (mRNA) (MOREIRA et al., 1993). Conforme Klausner et al. (1996) essa degradação do mRNA do TNF- $\alpha$ é dose-dependente. Contudo, de maneira oposta aos seus efeitos supressores na produção de TNF- $\alpha$ por monócitos e macrófagos, também pode haver superindução de TNF- $\alpha$ dependente de IL-2 em linfócitos CD4 e CD8 tratados com o fármaco, demonstrando assim um mecanismo de ação elaborado e intrincado (FRANKS et al., 2004).

A atividade anti-inflamatória ocorre também por meio do bloqueio da ativação do NF-кB que, quando ativado, é um regulador chave de genes inflamatórios (como TNF- $\alpha$, IL-6 e IL-12), proteínas envolvidas na apoptose e também em fatores antiangiogênicos (como TNF- $\alpha$, IL-8 e VEGF fator de crescimento do endotélio vascular, o). Como consequência, o NF-kB tem importante papel na regulação de processos como proliferação e crescimento tumoral, apoptose e resposta imune, e ao inibir deste fator, a talidomida afeta todos esses processos (KEIFER et al., 2001).

Há ainda uma grande variedade de citocinas que podem ter papel importante na imunomodulação e que também são afetadas pelo fármaco. A droga é capaz de suprimir a geração de algumas enzimas pró-inflamatórias e citocinas como COX-2, IL-1 beta, fator de transformação do crescimento beta e IL-6, o que contribui para a ativação do receptor de células T, particularmente no subconjunto de células T-helper 1 (MELCHERT; LIST, 2007). O fármaco também pode aumentar algumas citocinas, como interleucinas 4 e 5 (STIRLING et al., 1997). De modo paradoxal e similar ao que ocorre com o TNF- $\alpha$, a secreção de IL-12 é suprimida pela talidomida quando há estimulação de monócitos, 
e aumentada quando há estimulação de células T. A IL-12 promove aumento de células T e células NK (natural killer) e estimula a produção de IFN- $\gamma$, sendo que este e a IL-12 têm atividade antitumoral e antiangiogênica (MELCHERT; LIST, 2007).

$\mathrm{O}$ fármaco é potente co-estimulador de células $\mathrm{T}-$ colabora por meio do complexo receptor de células $\mathrm{T}$, aumentando sua proliferação mediada por IL-2 e produção de IFN- $\gamma$. O efeito é maior no subconjunto CD8 das células T que no subconjunto CD4 (HASLETT et al., 1998). Também parece diminuir a relação entre linfócitos $\mathrm{T}$, aumentando a produção dos T-auxiliares e diminuindo a produção dos T-inflamatórios. Esse efeito interessa ao tratamento de condições como o eritema nodoso leproso, já que células T-helper são usualmente prevalentes nas lesões cutâneas durante episódios agudos (STIRLING et al., 1997).

A ação antiangiogênica da talidomida, antes associada apenas à teratogênese, hoje está associada a mecanismo potencialmente benéfico em doenças onde neoangiogênese é característica de malignidade (MELCHERT; LIST, 2007). Inibe a estimulação da angiogênese (D'AMATO, 1994) reduzindo os níveis de promotores da angiogênese como TNF- $\alpha$, VEGF e IL-6. Além disso, há diminuição de COX-2, levando a uma diminuição da síntese de prostaglandinas, as quais também estimulam angiogênese. Estudos realizados em córneas de coelhos agredidas por substância alcalina demostraram que a droga bloqueia a ação de potentes fatores angiogênicos como Fator de Crescimento Fibroblástico (bFGF) e o Fator de Crescimento Endotelial Vascular (ABBAS; FEROZE; HYMAN, 2002). Por último, há fortes indícios de que as propriedades antiangiogênicas ocorram em virtude da produção de um radical do tipo hidroxila que é tóxico, capaz de bloquear vasculogênese e angiogênese durante o desenvolvimento embrionário (SAUER et al., 2000).

A talidomida possui potencial terapêutico em muitas doenças. A ação imunomoduladora e antiangiogênica motivou investigação no tratamento de neoplasias, principalmente tumores sólidos e hematológicos (MELCHERT; LIST, 2007) e emprego contra alguns tipos de câncer foi muito bem sucedido. Ainda não é conhecido o mecanismo exato da sua atividade antineoplásica, mas é provável que a base dessa atividade seja inibição da angiogênese, imunomodulação e modulação de citocinas, tanto individualmente quanto combinadas (SINGHAL; MEHTA, 2001). Souza et al. (2012) consideram que ela tenha como alvo componentes múltiplos do microambiente tumoral, como angiogênese, inflamação e atividade proliferativa. Assim, parece interferir com diversos fatores do desenvolvimento do câncer, como alteração da expressão de citocinas, aumento da angiogênese, perda da adesão celular, alteração da apoptose e da resposta imunológica (BORGES et al., 2005).

Independentemente das características imunomoduladoras, a talidomida possui atividade antiproliferativa direta nas neoplasias hematológicas, inibindo a proliferação de linhas celulares de mieloma múltiplo e também em células de mieloma primário resistentes à quimioterapia usualmente empregada (LENTZSCH et al., 2003).

Conforme Keifer et al. (2001), suas ações na promoção de apoptose são evidentes em vários níveis de sinalização de receptores de morte celular, incluindo o ligante indutor da apoptose relacionado com o TNF (TRAIL), proteína da apoptose-2, aumento da sensibilidade ao Fas-ligante e suprarregulação da ativação da caspase-8. Além disso, estudos moleculares identificaram meios da ação da talidomida no tratamento de mieloma múltiplo que incluem inibição da angiogênese na medula óssea, redução da adesão celular e aumento de citotoxicidade de células NK (FRANKS et al., 2004).

Para haver crescimento tumoral há necessidade de formação de extensa rede de capilares para fornecer nutrientes e oxigênio. Em pessoas, um dos fatores prognósticos que se correlacionam positivamente com sua agressividade é o grau de vascularização do tumor, sugerindo que mudanças na vascularização são necessárias à progressão tumoral (BOLONTRADE et al., 1998). A formação de novos vasos ou a angiogênese é fundamental para a proliferação e para a ocorrência de metástase na maioria das neoplasias malignas, sendo que em sua ausência o tumor não é capaz de se desenvolver além de 1-2mm, em relação a tamanho. $\mathrm{O}$ aumento da angiogênese é fator prognóstico adverso em tumores sólidos e em neoplasias hematológicas, como o mieloma (KUMAR et al., 2002). Assim, a ação antiangiogênica do fármaco também pode constituir um fator benéfico no tratamento de doenças oncológicas.

A talidomida inibe a produção do TNF- $\alpha$, fator capaz de induzir a perda de coesão de células epiteliais, facilitando a ocorrência de metástases. Essa capacidade seria devida à baixa expressão da molélula de adesão intercelular E-caderina, ocasionando dissociação das células epiteliais, relacionada à perda da diferenciação tumoral, aumento de invasividade e desenvolvimento de metástases (BORGES et al., 2005).

O fármaco também inibe a produção de IL-6, IL-10 e IL-12. A IL-6 é um potente fator de crescimento para células neoplásicas do plasma, e sua inibição pode ser parcialmente responsável pela ação no mieloma. Além de aumentar a contagem total de leucócitos e linfócitos T CD4 e CD8, é ainda um potente estimulador de linfócitos T. Paralelamente, ocorre aumento da IL-2, que tem atividade antitumoral e pode também induzir resposta ao câncer por modulação do sistema imune (SINGHAL; MEHTA, 2001). A Tabela 1 apresenta os principais mecanismos potenciais de ação da talidomida que podem contribuir para sua ação antineoplásica.

Tabela 1: Mecanismos potenciais para ação antineoplásica da talidomida (SINGHAL; MEHTA, 2001)

Inibição da angiogênese

Alteração de adesão de moléculas

Inibição da produção de TNF- $\alpha$

Indução da produção de citocinas de células T helper 2 (IL-4 e IL-5)

Efeito variável na produção de IFN- $\gamma$

Aumento da síntese de IL-2 por células mononucleares

Aumento de níveis solúveis de receptores de IL-2

Inibição da produção de IL-6, IL-10 e IL-12

Aumento de linfócitos totais e de linfócitos T CD4 e CD8

Co-estimulação de linfócitos T 


\section{Aplicações clínicas da talidomida em seres humanos}

O uso da talidomida como fármaco alternativo na dermatologia médica já é consideravelmente grande, sendo considerada efetiva em mais de 20 dermatoses de etiologia inflamatória ou auto-imune, como eritema nodoso leproso, doença de Behçet, lúpus eritematoso, sarcoidose e doença do enxerto contra hospedeiro. Segundo Borges et al. (2005), além de suas já mencionadas ações anti-inflamatórias e imunomoduladoras, aumenta também a proliferação e migração de ceratinócitos, sendo útil em condições de reepitelização deficiente.

A talidomida é o fármaco de escolha no tratamento de eritema nodoso leproso (ENL) sintomático moderado a severo (TEO et al., 2002), que é uma complicação da hanseníase, sendo caracterizado por nódulos eritematosos dolorosos cutâneos e subcutâneos (MATTHEWS; McCOY, 2003). Sua eficácia se deve principalmente à ação sobre o TNF, porém outros mecanismos podem contribuir para o efeito anti-inflamatório (SAMPAIO et al., 1993). As lesões granulomatosas cutâneas de sarcoidose são similares, e também foram efetivamente controladas com seu uso, segundo FRANKS et al. (2004).

A Doença de Behçet é uma enfermidade sistêmica que ocasiona lesões dermatológicas, panuveíte, artrite, hemorragia intestinal e úlceras orogenitais recorrentes (HAMURYUDAN et al., 1998). O uso de talidomida induz rápida resolução das úlceras orogenitais, porém sem melhoria nos sinais oculares e de artrite (DE WAZIĖRES et al., 1999; SHEK; LIM, 2002). De acordo com Wu et al. (2005), como algumas das úlceras podem ter resolução espontânea, esse tratamento deve ser reservada para aos casos graves.

A talidomida é considerada a segunda escolha terapêutica para o lúpus eritematoso cutâneo grave, com taxa de resposta clínica de 84 a $100 \%$ e possibilidade de terapia de manutenção após a resposta inicial, principalmente nos pacientes refratários a outros tratamentos (FRANKS et al., 2004).

A doença crônica do enxerto contra hospedeiro é a complicação frequente após transplante de medula óssea, acometendo a pele de aproximadamente $40 \%$ dos pacientes que sobrevivem 100 dias após o transplante (SULLIVAN et al., 1988), e segundo Franks et al. (2004) a talidomida pode atuar como imunossupressor adjuvante à terapia convencional. Há relatos que indicam-na em dermatoses como piodermite granulomatosa, prurigo nodular, porfiria cutânea tardia, líquen plano, prurigo actínico, eritema multiforme, histiocitose das células de Langerhans, prurido urêmico, alopecia areata e pênfigo (FRANKS et al., 2004; ORDI-ROS et al., 2010). Já em caso de necrólise epidérmica tóxica, doença associada com atividade aumentada de TNF- $\alpha$, o fármaco é contraindicado (CHEN et al., 2010).

A talidomida pode ter ação no tratamento de afecções gastrintestinais, como estomatite aftóide (CHEN et al., 2010). Em um estudo clínico aberto, sua eficácia no tratamento da estomatite aftóide foi comparada com dapsona, colchinina e pentoxifilina, sendo o fármaco mais efetivo e bem tolerado, com remissão completa do quadro em sete de oito pacientes (MIMURA et al., 2009). Além disso, foi eficaz também no tratamento da estomatite aftosa recorrente em pacientes portadores de Síndrome da Imunodeficiência Adquirida (AIDS). As estomatites aftóides possuem curso variável e em muitos casos podem se resolver espontaneamente, portanto, o uso do fármaco deve ser reservado para casos mais severos, recorrentes e de difícil resolução (CHEN et al., 2010). A doença de Crohn é uma doença inflamatória sistêmica recorrente, que afeta principalmente o trato gastrintestinal, mas também induz manifestações extra-intestinais e distúrbios imunológicos associados (BAUMGART; SANDBORN, 2012). A enfermidade é mediada em parte por TNF- $\alpha$ e IL-12, e foi efetivamente controlada por curtos períodos de uso de talidomida, em pacientes dependentes de corticoterapia. Ademais, a melhora clínica foi demonstrada na frequência de defecações, nas fístulas e no índice de atividade da doença, e as respostas positivas variaram de 50 a $70 \%$ (FRANKS et al., 2004).

Caquexia e perda de peso são comuns nos estágios avançados da AIDS, e alguns estudos mostram aumento no peso de pacientes tratados com talidomida (PEUCKMANN; FISCH; BRUERA, 2000; KAPLAN et al., 2000). Ela foi efetiva também para tratamento de lesões gastrintestinais e mostrou atividade moderada em pacientes soropositivos com sarcoma de Kaposi (CHEN et al., 2010). Além disso, existe a possibilidade do fármaco exercer atividade anti-HIV por meio da interferência na produção do TNF- $\alpha$, que induz diretamente a expressão do HIV na célula infectada, por estímu-

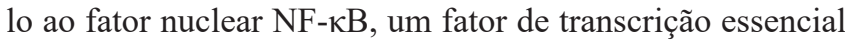
para a expressão do HIV (POLI et al., 1990). O TNF- $\alpha$ é também considerado relevante no quadro de caquexia (BORGES; FRÖEHLICH, 2003).

A insuficiência cardíaca congestiva avançada é caracterizada por níveis elevados de mediadores inflamatórios, incluindo o TNF- $\alpha$, e a talidomida foi capaz de bloquear a síntese de TNF- $\alpha$ pelos miócitos cardíacos em resposta à estimulação de lipopolissacarídeos, induzindo melhora em variáveis clínicas como capacidade funcional e fração de ejeção (DAVEY; ASHRAFIAN, 2000; AGOSTON et al., 2002).

Considerando que a atividade anti-tumoral do fármaco provém principalmente da inibição da angiogênese e do estímulo à resposta imune, sua eficácia tem sido explorada especial e predominantemente em tipos de neoplasia nos quais essas características são consideradas importantes do ponto de vista fisiopatológico. Um ponto positivo de grande valor no seu uso, em comparação a outros fármacos geralmente utilizados em oncologia, é a ausência de mielossupressão grave, efeito colateral comum a muitos agentes quimioterápicos. Mielossupressão ocorreu em somente cerca de $5 \%$ dos pacientes tratados com talidomida, sendo que desses um número considerável havia sido previamente tratado com outros quimioterápicos (SLEIJFER et al., 2004). O fármaco também é capaz de beneficiar os pacientes caquéticos em termos de apetite, sono e náuseas (FRANKS et al., 2004). Também tem sido empregada com sucesso como parte do protocolo quimioterápico em neoplasmas sólidos como câncer renal e gliomas de alto grau, para metástases de câncer prostático, e ainda para neoplasias hematológicas como leucemia e linfoma, sendo que atualmente sua principal indicação é o mieloma múltiplo (BARTLETT; DREDGE; DALGLESISH, 2004). Existe ainda perspectiva de utilização para vários outros tipos de neoplasmas, inclusive mamários (BAIDAS et 
al., 2000).

O uso da talidomida no tratamento de mieloma múltiplo tem como base a existência de neovascularização elevada na medula óssea de pacientes com doença progressiva, e sua capacidade de inibir angiogênese. Recentemente seu uso emergiu em vários relatos como protocolo-padrão, tanto como tratamento de primeira escolha quanto para as formas refratárias e recidivantes de mieloma múltiplo (MELCHERT; LIST, 2007). Demonstrou-se que a combinação de talidomida e dexametasona tem efeito sinérgico e induz resposta parcial, de 60 a $70 \%$, até mesmo em pacientes refratários a quaisquer agentes empregados individualmente (WEBER, 2003).

Os carcinomas de células renais secretam VEGF e TNF- $\alpha$, embasando o uso da talidomida, e a taxa real de recuperação empregando-a como terapia única ou em combinação com gemcitabina e fluoracila foi de 0 a $10 \%$, com algum efeito na estabilidade da doença (26 a 32\%) (FRANKS et al., 2004).

Os gliomas de alto grau geralmente são acompanhados de aumento na vascularidade e na densidade de microvasos, e a talidomida oferece alguns benefícios nessas afecções que possuem prognóstico desfavorável (glioma anaplásico misto, astrocitoma anaplásico e gliobastoma multiforme) (FRANKS et al., 2004).

Outro tipo de neoplasia no qual a talaidomida demonstrou atividade anti-tumoral foi o câncer de próstata hormônio-independente, com significativa redução de antígeno prostático específico (PSA) em 30 a 40\% dos pacientes (SLEIJFER et al., 2004). Além disso, também demonstrou atividade em câncer colorretal (FRANKS et al., 2004), e interfere na capacidade de células embólicas tumorais de osteossarcoma canino de completar o processo metastático nos pulmões (FARESE et al., 2004).

\section{Análogos da talidomida}

O complexo e intrigante mecanismo de ação da talidomida estimulou pesquisadores a buscar compostos derivados ou baseados em sua molécula, muitos com atividade potencializada ou ainda com redução dos efeitos colaterais do fármaco-mãe. Foram desenvolvidas duas classes de fármacos análogos, os imunomoduladores (DIMs) e os inibidores seletivos de citocinas (DISelCs). Em modelos pré-clínicos, ambas as classes inibiram crescimento tumoral e angiogênese, por vezes de forma mais eficiente até que a própria talidomida. A diferença está em DIMs co-estimularem células T, ao contrário DISelCs (SLEIJFER et al., 2004). Alguns estudos também já foram realizados com análogos, que demonstraram ser seguros e apresentaram efeitos anti-neoplásicos convincentes, in vitro para tumores prostáticos, e clinicamente no mieloma múltiplo e em alguns tumores sólidos (FRANKS et al., 2004; SLEIJFER et al., 2004).

\section{Uso da talidomida em medicina veterinária}

A talidomida e seus análogos foram exaustivamente testados em animais para investigação de efeitos colaterais, na maioria das vezes usando camundongos, ratos e hamsters. Existem ainda estudos em coelhos (ABBAS et al., 2002), co- baios (CORNEA; VLADUTIU; MARCOVICI, 1967) e cães (TEO et al., 2001).

Apesar disso, o real uso clínico da talidomida em medicina veterinária ainda é incipiente, provavelmente em função do desconhecimento do mecanismo de ação, e consequentemente de suas potenciais aplicações veterinárias, dos vários empecilhos legais para sua prescrição e utilização clínica ou mesmo experimental, e do receio e preconceito em empregar o fármaco.

Ainda assim, há relatos de uso bem sucedido e sem efeitos colaterais em curto prazo em cães, em hemangiossarcoma (WOODS; MATHEWS; BINNINGTON; 2004), e em mesotelioma pericárdico maligno, carcinoma nasal, osteossarcoma, carcinomatose abdominal e carcinoma hepatocelular JANKOWSKI et al., 2009). Adicionalmente, a talidomida já foi empregada em associação à lactoferrina, no tratamento da estomatite viral e para evitar a disseminação de calicivirus, em gatos (ADDIE et al., 2003).

O sucesso terapêutico já observado em diversas situações clínicas em pessoas e em testes com animais poderia ser extrapolado com certo grau de confiança para doenças homólogas nos animais, como estomatites, lúpus, pênfigo, alopecia areata, mieloma, amiloidose, linfoma, carcinoma renal, câncer de próstata, síndromes mielodisplásicas, leucemias, colite, artrite reumatóide, insuficiência cardíaca, anorexia e caquexia do câncer.

\section{Legislação brasileira atual}

Em decorrência de uma nova geração de vítimas da ação teratogênica da talidomida no Brasil, a Portaria $n^{\text {. }} 63$ da Secretaria de Vigilância Sanitária do Ministério da Saúde proibiu, em Julho de 1994, a prescrição do fármaco a mulheres em idade fértil em todo território nacional (OLIVEIRA et al., 1999).

Registro, fabricação, produção, comercialização, exposição, prescrição e dispensação de produtos à base de talidomida são regulamentados pela portaria $n^{\text {o. }} 354 / 97$ da ANVISA. Nela constam ainda as modernas indicações clínicas para seu uso, no âmbito de programas governamentais: hanseníase (reação hansênica tipo Eritema Nodoso ou Tipo II), DST/AIDS (úlceras aftóides idiopáticas nos pacientes portadores de HIV/AIDS) e doenças crônico-degenerativas (lúpus eritematoso, doenças enxerto-versus-hospedeiro). A utilização para tratamento de mieloma múltiplo refratário à quimioterapia foi acrescentada pela Resolução RDC n ${ }^{\circ}$ 34/00 (MEIRA et al., 2004). A Lei 10.651 dispõe sobre o controle do uso da talidomida, que deve ser prescrita em formulário especial numerado, com retenção pela farmácia e envio ao órgão de vigilância sanitária. A bula deve conter informações sobre os efeitos teratogênicos, e ser acompanhada de termo de responsabilidade a ser obrigatoriamente assinado por médico e paciente no ato da entrega do medicamento.

Sua distribuição, deverá ser feita exclusivamente pelos programas expressamente qualificados pelo governo, que deverão oferecer orientação aos usuários sobre os riscos teratogênicos em gestantes, e oferecer métodos contraceptivos às mulheres em idade fértil (VIANNA, 2013).

\section{Considerações Finais}


A tragédia da utilização da talidomida causa reflexos até hoje, e obviamente resultou em preconceito e fortes reações à mera menção do nome do fármaco. Defensores da causa do bem-estar animal usam a situação para disseminar a ideia de que o teste de fármacos em animais é ineficiente e desnecessário, uma vez que o fármaco foi testado e não demonstrou ser teratogênico nos roedores do mesmo modo que é nas pessoas.

Surpreendentemente, pesquisas subsequentes demonstraram que ela tem alta eficiência terapêutica em uma série de doenças dermatológicas, cardíacas, gastrintestinais, imunodepressoras e neoplásicas, bem como na caquexia devida a câncer e AIDS. Muitos desses resultados foram promissores e comprovados não apenas experimentalmente, mas também pelo uso clínico em pessoas enfermas, reavivando a possibilidade de que a talidomida seja aquele fármaco extraordinário que um dia se pensou que fosse.

Adicionalmente, à exceção da óbvia ação teratogênica embrionária, seu uso induz relativamente poucos efeitos colaterais. O grande desafio atual não são os apavorantes efeitos colaterais da administração a gestantes, mas sim o preconceito e a legislação draconiana vigente no país. Ao contrário dos ativistas contrários ao uso de animais em testes farmacológicos, que usam a talidomida como "prova" de que "experimentação animal não funciona", é possível afirmar categoricamente que o desastre da talidomida ocorreu justamente em função do pouco emprego de experimentação animal na fase de testes.

Isso decorre da lógica dos fatos investigados na história do fármaco. Diferentes animais demonstram grande variedade de respostas a distintos fármacos, e especificamente em relação a esse fármaco, as ações teratogênicas são variáveis nas diferentes ordens de mamíferos. Atualmente é sabido que coelhos e macacos-rhesus teriam sido animais mais apropriados para testes farmacológicos de teratogenia. No caso da talidomida, uma das principais falhas foi não realizar os testes necessários em animais de outras espécies e ordens zoológicas antes da liberação do fármaco no mercado - ao invés de somente roedores, deveriam ter sido empregados também lagomorfos e primatas.

A criação e consequente evolução dos fármacos análogos ajudarão na melhor compreensão do mecanismo de ação do fármaco-mãe em nível molecular, trazendo ainda a possibilidade de aprimorar tal mecanismo, produzindo fármacos sucessores mais eficientes e seguros, que ajudarão a combater o preconceito e o pessimismo que sempre cercaram o uso desse fármaco, outrora agressor e agora certamente considerado promissor.

Por fim, resta afirmar que embora seu potencial seja inegável, ainda é inexplorado, e isso é lamentável, pois muitas das doenças nas quais a talidomida demonstrou ser eficiente no tratamento de pessoas, também ocorrem em outras espécies de grande interesse veterinário, como os animais de companhia.

\section{Referências}

ABBAS, A.; FEROZE, A. H.; HYMAN, G. F. Thalidomide prevents corneal angiogenesis in an alkali burn model of rabbit corneal neovascularization. Journal of Pakistan

Medical Association, Karachi, Pakistan, v. 53, n. 5, p. 183186, maio 2003.

ADDIE, D. D. et al. Cessation of feline calicivirus shedding coincident with resolution of chronic gingivostomatitis in a cat. Journal of Small Animal Practice, New Jersey, v. 44, n. 4, p.172-176, abr. 2003.

AGOSTON, I. et al. Preclinical and clinical assessment of the safety and potential efficacy of thalidomide in heart failure. Journal of Cardiac Failure, Amsterdan, Neteherlands, v. 8, n. 5, p. 306-314, out. 2002.

BAIDAS, S. M. et al. Phase II evaluation of thalidomide in patients with metastatic breast cancer. Journal of Clinical Oncology, v. 18, n. 14, p. 2710-2717, jul. 2000.

BARTLETT, J.; DREDGE, K.; DALGLESISH, A. The evolution of thalidomide and its IMiD derivatives as anticancer agents. Nature Reviews Cancer, London, v. 4, n. 4, p. 314-321, abr. 2004.

BAUMGART, D. C.; SANDBORN, W. J. Crohn's disease. The Lancet, Amsterdan, Netherlands, v. 380, n. 9853, p. 1590-1605, nov. 2012.

BOLONTRADE, M. F. et al. Angiogenesis is an early event in the development of chemically induced skin tumors. Carcinogenesis, Oxford, v. 19, n. 12, p. 2107-2113, dez. 1998.

BORGES, L. G.; FRÖEHLICH, P. E. Talidomida - Novas perspectivas para utilização como anti-inflamatório, imunossupressor e antiangiogênico. Revista da Associação Médica Brasileira, São Paulo, v. 49, n. 1, p. 96-102, jan./ mar. 2003.

BORGES, L. V.; GUERRA, M. de O; AARESTRUP, F. M. Talidomida: de teratogênica à terapêutica. Boletim do Centro de Biologia da Reprodução, Juiz de Fora, v. 24, p. 31-44, 2005.

CHEN, M.; DOHERTY, S. D.; HSU, S. Innovative uses of thalidomide. Dermatologic Clinics, Amsterdan, Netherlands, v. 28, n. 3, p. 577-586, jul. 2010.

CHRISTIE, G. A. Thalidomide and congenital abnormalities, The Lancet, Amsterdan, Netherlands, v. 280, n. 7249 , p. 249, Aug. 1962.

CORNEA, P.; VLADUTIU, A.; MARCOVICI, G. The immuno-suppressive effect of thalidomide in experimental tuberculosis in guinea-pigs. Tubercle, Amsterdan, Netherlands, v. 48, n. 1, p. 51-53, Mar. 1967.

D'AMATO, R. J. et al. Thalidomide is an inhibitor of angiogenesis. Proceedings of the National Academy of Sciences of the United States of America, Washington, v. 91, n. 9, p. 4082-4085, 1994. 
D'ARCY, P. F.; GRIFFIN, J. P. Thalidomide revisited. Adverse Drug Reactions and Toxicological Reviews, London, v. 13, n. 2, p. 65-76, 1994.

DAVEY, P. P.; ASHRAFIAN, H. New therapies for heart failure: is thalidomide the answer? QJM: An International Journal of Medicine, Oxford, v. 93, n. 5, p. 305-311, May 2000 .

DE WAZIÈRES, B. et al. Treatment of recurrent ulceration with low doses of thalidomide. Pilot study in 17 patients.

La Revue de Médecine Interne, Amsterdan, Netherlands, v. 20, n. 7, p. 567-570, July 1999.

\section{ERIKSSON, T.; BJÖRKMAN, S.; HÖGLUND, P.P.} Clinical pharmacology of thalidomide. European Journal of Clinical Pharmacology, Berlin, v. 57, n. 5, p. 365-376, Aug. 2001.

FARESE, J. P. et al. Effect of thalidomide on growth and metastasis of canine osteosarcoma cells after xenotransplantation in athymic mice. American Journal of Veterinary Research, v. 65, p. 659-664, 2004.

FERNÁNDEZ-CAMACHO, Y.; LEON-DORANTES, G. Talidomida: una nueva oportunidad. Revista Médica del Hospital General de México, Delegación Benito Juárez, México, v. 63, n. 3, p. 185-191, jul./sept. 2000.

FRANKS, M. E.; MACPHERSON, G. R.; FIGG, W. D. Thalidomide. The Lancet, Amsterdan, Netherlands, v. 363, n. 9423, p. 1802-1811, maio 2004.

HAMURYUDAN, V. et al. Thalidomide in the treatment of the mucocutaneous lesions of the Behçet syndrome. A randomized, double-blind, placebo-controlled trial. Annals of Internal Medicine, Philadelphia, v. 128, n. 6, p. 443450, May 1998.

HASLETT, P. A. J. et al. Thalidomide costimulates primary human T lymphocytes, preferentially inducing proliferation, cytokine production, and cytotoxic responses in the CD8+ subset. Journal of Experimental Medicine, New York, v. 187, n. 11, p. 1885-1892, jun. 1998.

JACOBSON, J. M. Thalidomide: a remarkable comeback. Expert Opinion on Pharmacotherapy, Zug, Switzerland, v. 1, n. 4, p. 849-863, May 2000.

JANKOWSKI, M. et al. Ongoing evaluation of single agent thalidomide in dogs with measurable cancer. Proceedings... Veterinary Cancer Society - 19th Annual Meeting, Wood's Hole, MA, 2009.

KAPLAN, G. et al. Thalidomide for the treatment of AIDS-associated wasting. AIDS Research and Human Retroviruses, New Rochelle, v. 16, n. 14, p. 1345-1355, Sep. 2000.

KEIFER, J. A. et al. Inhibition of NF- $\mathrm{BB}$ activity by thalidomide through suppression of I $\mathrm{B}$ kinase activity.
Journal of Biological Chemistry, Rockville, v. 276, n. 25, p. 22382-22387, June 2001.

KLAUSNER, J. D.; FREEDMAN, V. H.; KAPLAN, G. Short analytical review: thalidomide as an antiTNF- $\alpha$ inhibitor: implications for clinical use. Clinical Immunology and Immunopathology, Amsterdan Netherlands, v. 81, n. 3, p. 219-223, Dec. 1996.

KUMAR, S.; WITZIG, T. E.; RAJKUMAR, S. V. Thalidomide as an anti-cancer agent. Journal of Cellular and Molecular Medicine, Malden, v. 6, n. 2, p. 160-174, Apr. 2002.

KUMAR, S.; WITZIG, T. E.; RAJKUMAR, S. V. Thalidomide as an anti-cancer agent. Journal of Cellular and Molecular Medicine, Malden, v. 6, n. 2, p. 160-174, Apr./June 2002.

LENTZSCH, S. et al. Immunomodulatory analogs of thalidomide inhibit growth of Hs Sultan cells and angiogenesis in vivo. Leukemia, London, v. 17, n. 1, p. 4144, Jan. 2003

LENZ, W. A short history of thalidomide embryopathy. Teratology, Malden, v. 38, n. 3, p. 203-215, Sept. 1988

LIMA, L. M.; FRAGA, C. M.; BARREIRO, E. J. O renascimento de um fármaco: talidomida. Química Nova, São Paulo, v. 24, n. 5, p. 683-688, set./out. 2011.

MARRIOTT, J. B.; WESTBY, M.; DALGLEISH, A. G. Therapeutic potential of TNF- $\alpha$ inhibitors old and new. Drug Discovery Today, Amsterdan, v. 2, n. 7, p. 273-282, June 1997.

MATTHEWS, S. J.; MCCOY, C. Thalidomide: a review of approved and investigational uses. Clinical therapeutics, Amsterdan, v. 25, n. 2, p. 342-395, fev. 2003.

MEIRA, M. E. C.; BITTENCOURT, M. O.; NEGREIROS, R. L. Talidomida: revisão bibliográfica e atualização da bula, conforme Resolução RDC no 140/03. In: GARCIA, M.; PEPE, V. L. E.; ANDRADE, C. R.; PONTES JÚNIOR, D. M. (Org.) Coleção Escola de Governo - Série Trabalhos de Alunos - Vigilância em Saúde. Rio de Janeiro: Escola de Governo em Saúde, 2004. p. 81-133.

MELCHERT, M.; LIST, A. The thalidomide saga. The International Journal of Biochemistry \& Cell Biology, Amsterdan, Netherlands, v. 39, n. 7-8, p. 1489-1499, July/ Aug. 2007.

MIMURA, M. A. et al. Systemic treatment in severe cases of recurrent aphthous stomatitis: an open trial. Clinics, São Paulo, v. 64, n. 3, p. 193-198, Mar. 2009.

MOREIRA, A. L. et al. Thalidomide exerts its inhibitory action on tumor necrosis factor $\alpha$ by enhancing mRNA degradation. Journal of Experimental Medicine, New York, v. 177, n. 6, p. 1675-1680, June 1993. 
NEUBERT, R.; MERKER, H-J.; NEUBERT, D.

Developmental model for thalidomide action. Nature, London, v. 400, n. 6743, p. 419-429, July 1999.

NEWMAN, C. G. H. The Thalidomide syndrome: risks of exposure and spectrum of malformations. Clinics in Perinatology, Maryland Heights, v. 13, n. 3, p. 555-573, Sept. 1986.

NG, S. S. W.; BROWN, M.; FIGG, W. D. Thalidomide, an antiangiogenic agent with clinical activity in cancer. Biomedicine and Pharmacotherapy, Amsterdan, v. 56, n. 4, p. 194-199, June 2002 .

OLIVEIRA, M. A.; BERMUDEZ, J. A.; SOUZA, A. C. M. Talidomida no Brasil: vigilância com responsabilidade compartilhada? Cadernos de Saúde Pública, Rio de Janeiro, v. 15, n. 1, p. 99-112, jan./mar. 1999.

ORDI-ROS, J.; COSIGLIO, F. J. Indicaciones terapéuticas actuales de la talidomida y la lenalidomida. Medicina Clínica, Amsterdan, v. 142, n. 8, p. 360-364, abr. 2010.

PEUCKMANN, V.; FISCH, M.; BRUERA, E. Potential novel uses of thalidomide: focus on palliative care. Drugs, Berlin, v. 60, n. 2, p. 273-292, Sept. 2000.

POLI, G. et al. Tumor necrosis factor alpha functions in an autocrine manner in the induction of human immunodeficiency virus expression. Proceedings of the National Academy of Sciences, Washington, v. 87, n. 2, p. 782-785, Jan. 1990.

POLITI, P. M. Talidomida: ensayos clinicos en cancer. Medicina (Buenos Aires), Buenos Aires, v. 60, supl. 2, p. $61-65,2000$

RAJKUMAR, S. V. Thalidomide: tragic past and promising future. Mayo Clinic Proceedings, Rochester, v. 79, n. 7, p. 899- 903, July 2004.

SAMPAIO, E. et al. The influence of thalidomide on the clinical and immunology manifestation of erythema nodoso leprosum. Journal of Infectious Diseases, Oxford, v. 168, n. 2, p. 408-414, Aug. 1993.

SAUER, H. Thalidomide inhibits angiogenesis in embryoid bodies by the generation of hydroxyl radicals. American Journal of Pathology, v. 156, p. 151-158, 2000.

SCIALLI, A. R. A Clinical guide to reproductive and developmental toxicology. Boca Raton: CRC Press, 1992.

SHARDEIN, J. L. Psychotropic drugs. In: SHARDEIN, J. L. Chemically induced birth defects, 2. ed. Nova Iorque: Marcel Dekker, 1993. p. 208-270.

SHEK, L. P.; LIM, D. L. Thalidomide in Behçet disease. Biomedicine \& Pharmacotherapy, Amsterdan, v. 56, n. 1, p. 31-35, Feb. 2002.
SHESKIN, J. Further observation with thalidomide in lepra reactions. Leprosy Review, Colchester, Essex, v. 36, n. 4, p. 183-187, Oct. 1965.

SINGHAL, S.; MEHTA, J. Thalidomide in cancer potential uses and limitations. BioDrugs, New York, v. 15, n. 3, p. 163-172, Jan. 2001

SLEIJFER, S.; KRUIT, W. H. J.; STOTER, G. Thalidomide in solid tumours: the resurrection of an old drug. European Journal of Cancer, v. 40, n. 16, p. 2377-2382, Nov. 2004.

SOUZA, C. M. et al. Thalidomide attenuates mammary cancer associated-inflammation, angiogenesis and tumor growth in mice. Biomedicine \& Pharmacotherapy, Amsterdan, Netherlands, v. 66, n. 7, p. 491-498, out. 2012.

STEPHENS, T. D.; BUNDE, C. J. W.; FILLMORE, B. $\mathrm{J}$. Mechanism of action in thalidomide teratogenesis. Biochemical Pharmacology, Amsterdan, Netherlands, v. 59, n. 12, p. 1489-1499, jun. 2000.

STIRLING, D.; SHERMAN, M.; STRAUSS, S. Thalidomide. A surprising recovery. Journal of the American Pharmaceutical Association, Washington, v. NS 37, n. 3, p. 306-313, May/June 1997.

SULLIVAN, K. M. et al. Alternating-day cyclosporine and prednisone for treatment of high-risk chronic graft-v-host disease. Blood, Washington, v. 72, n. 2, p. 555-561, Aug. 1988.

TABIN, C. J. A developmental model for thalidomide defects. Nature, London, v. 396, n. 6709, p. 322-323, Nov 1998.

TEO, S. K. et al. Clinical pharmacokinetics of thalidomide. Clinical Pharmacokinetics, New York v. 43, n. 5, p. 311327, Apr. 2004.

TEO, S. K. et al. Safety profile of thalidomide after 53 weeks of oral administration in beagle dogs. Toxicological sciences: an official journal of the Society of Toxicology, Oxford, v. 59, n. 1, p. 160-168, Jan. 2001.

TEO, S. K. et al. Thalidomide in the treatment of leprosy. Microbes And Infection, Amsterdan, Netherlands, v. 4, n. 11, p. 1193-1202, Sept. 2002.

VIANNA, F. S. L. Uso atual de talidomida e defeitos congênitos no Brasil, Porto Alegre, 2013. 135 f.

Dissertação (Mestrado em Genética e Biologia Molecular) - Universidade Federal do Rio Grande do Sul, Porto Alegre, 2013.

WEBER, B. Thalidomide and its derivatives: new promise for multiple myeloma. Cancer Control: Journal of the Moffitt Cancer Center, v. 10, n. 5, p. 375-383, Sept./Oct. 2003.

WOODS, J. P.; MATHEWS, K. A.; BINNINGTON, A. G. 
Thalidomide for the treatment of hemangiosarcoma in dogs. Veterinary and Comparative Oncology, New Jersey, v. 2, n. 2, p. 108-109, June 2004.

WU, J. J. et al. Thalidomide: dermatological indications, mechanisms of action and side-effects. British Journal of Dermatology, Southern Gate, v. 153, n. 2, p. 254-273, Aug. 2005.

Recebido em: 25.05.2014

Aceito em: 20.03.2015 